\title{
ENERGIES AND MIXING RATIOS OF TRANSITIONS IN ${ }^{{ }^{72}} \mathbf{G e}^{\dagger}$
}

\author{
HSUAN CHEN \\ Phy sics Department, Saginaw Valley College, University Center, Michigan 48710 \\ and \\ P L. GARDULSKI and M. L. WIEDENBECK \\ Physics Department, University of Michigan, Ann Arbor, Michtgan 48104
}

Recelved 22 October 1973

\begin{abstract}
The lower energy $\gamma$-rays of ${ }^{72} \mathrm{Ge}$ from the decay of $14 \mathrm{~h}{ }^{72} \mathrm{Ga}$ have been studied using a $2 \mathrm{~m}$ curved-crystal spectrometer. Mixing ratios for the 601, 630, 894 and $1051 \mathrm{keV}$ transitions were determined from the $\gamma-\gamma$ directional correlations The E0 content of the $630 \mathrm{keV}, 2^{+\prime} \rightarrow 2^{+}$ transition was found to be less than $2 \%$. A spin of 3 for the $2065 \mathrm{keV}$ level has been uniquely determined
\end{abstract}

E

RADIOACTIVITY ${ }^{72} \mathrm{Ga}$ [from ${ }^{71} \mathrm{Ga}(\mathrm{n}, \gamma)$ ]; measured $E_{\gamma}, \gamma \gamma(\theta) .{ }^{72} \mathrm{Ge}$ deduced mixıng ratıos, spin Curved-crystal spectrometer and $\mathrm{Ge}\left(\mathrm{L}_{1}\right)$ detectors

\section{Introduction}

The level scheme of ${ }^{72} \mathrm{Ge}$ has been investigated by various authors ${ }^{1-10}$ ). It has been established that ${ }^{72} \mathrm{Ge}$ is a deformed nucleus, whose low lying level structure can be explained by a vibrational model. Recently, Camp ${ }^{1}$ ) and Rester et al. ${ }^{2,3}$ ) have measured the $\gamma$-ray energies of transitions in ${ }^{72} \mathrm{Ge}$ occurring in the decays of $14.1 \mathrm{~h}$ ${ }^{72} \mathrm{Ga}$ and $26.0 \mathrm{~h}{ }^{72} \mathrm{As}$, using $\mathrm{Ge}\left(\mathrm{L}_{1}\right)$ detectors. However, some of their results, especrally the low energy transitions, have large uncertaintıes. In the present work, a curvedcrystal spectrometer was used to make precision energy measurements of many of the $\gamma$ rays below $900 \mathrm{keV}$. Two $\mathrm{Ge}\left(\mathrm{L}_{1}\right)$ detectors were used in the directional correlation measurements of the present study. The results from this system have much lower uncertainties than previous results ${ }^{9,10}$ ) and allow one to determine the mixing ratios of the 1051, 894, 630 and $601 \mathrm{keV}$ transitions. The E0 content of the $630 \mathrm{keV}$ transition was determıned for the first tıme by a method proposed by Anıcın et al. ${ }^{11}$ )

\section{Energy determination}

The radioactive ${ }^{72} \mathrm{Ga}$ sources were prepared by neutron irradiation of natural gallium in the Unıversity of Michigan Ford Reactor. The $\gamma$-ray energies occurring in the $\beta$-decay of ${ }^{72} \mathrm{Ga}$ were measured with a $2 \mathrm{~m} \mathrm{Ge}(0 \overline{2} 2)$ curved-crystal spectrometer

† Work supported in part by a grant from the National Science Foundation 
H. CHEN et al.

TABLE 1

Energies (in keV) of $\gamma$-rays in ${ }^{72} \mathrm{Ge}$ from the decay of ${ }^{72} \mathrm{Ga}$

\begin{tabular}{cll}
\hline Present measurement & (amp ${ }^{\mathrm{a}}$ ) & Rester et al. ${ }^{\mathrm{b}}$ ) \\
\hline $289.313 \pm 0.066$ & $2895 \pm 02$ & $289.3 \pm 0.3$ \\
$336632 \pm 0.042$ & $3366 \pm 02$ & $3363 \pm 0.3$ \\
$381.242 \pm 0.080$ & $3812 \pm 02$ & $3812 \pm 02$ \\
$428417 \pm 0177$ & $428.4 \pm 02$ & $4283 \pm 03$ \\
$479228 \pm 0.098$ & $4796 \pm 03$ & $479.1 \pm 03$ \\
$587.440 \pm 0.240$ & $5874 \pm 0.3$ & $5879 \pm 04$ \\
$600.948 \pm 0.028$ & $6009 \pm 0.01$ & $60085 \pm 003$ \\
$629.956 \pm 0036$ & $6299 \pm 0.1$ & $62986 \pm 004$ \\
$786.438 \pm 0083$ & $786.5 \pm 0.1$ & $786.4 \pm 0.1$ \\
$810195 \pm 0.088$ & $810.2 \pm 02$ & $81024 \pm 009$ \\
$834.026 \pm 0034$ & $833.95 \pm 005$ & $83402 \pm 0.03$ \\
$894254 \pm 0094$ & $8942 \pm 01$ & $89422 \pm 005$ \\
\hline
\end{tabular}

a) $\operatorname{Ref}^{1}$ ).

b) Ref ${ }^{2}$ )

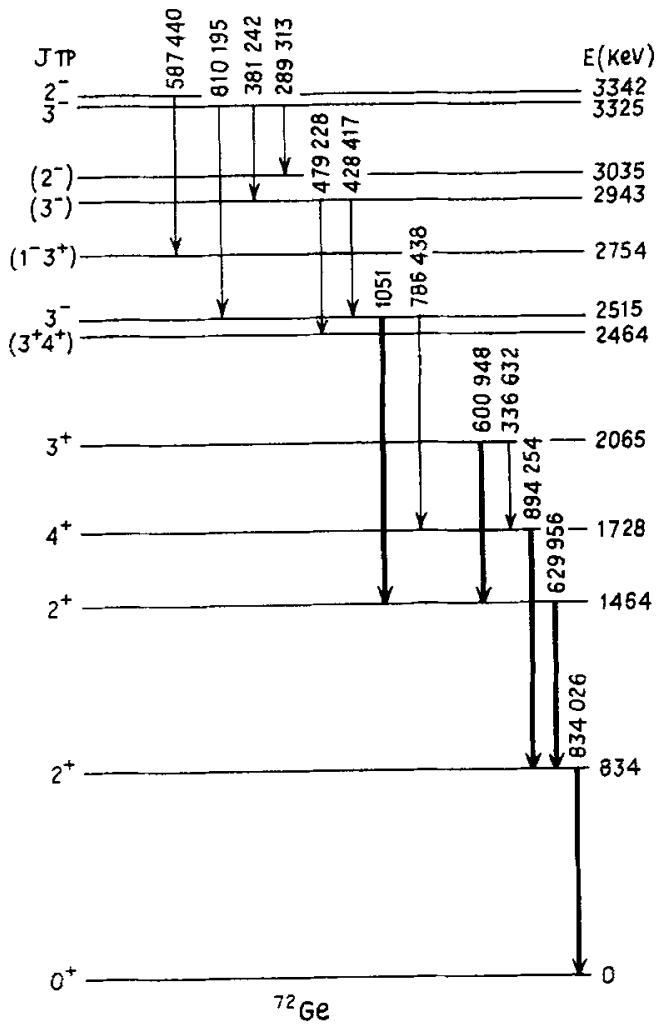

Fig. 1 An abbreviated level scheme for ${ }^{72} \mathrm{Ge}$ incorporating the curved-crystal energy measurements of this study The decay scheme is from refs. ${ }^{1.2}$ ) The transitions in heavy lines are the ones used in the directional correlation measurements 
described by Reidy and Wredenbeck ${ }^{12}$ ). Because of the low intensity of the low energy $\gamma$-rays, only twelve transitions could be measured. These energy results are presented in fig. 1 and table 1 . The results of Camp ${ }^{1}$ ) and Rester et al. ${ }^{2}$ ) are also presented in table 1 for comparison.

\section{Gamma-gamma directional correlations}

The directional correlation system and method of analysis have been described elsewhere ${ }^{13}$ ). The sign convention of the mixing ratios, $\delta$, is that of Biedenharn and Rose ${ }^{14}$ ) and Dzhelepov et al. ${ }^{16}$ ).

In this work, the 601-630, 1051-630,630-834, 894-834, 601-630-834 and 1051630-834 keV correlations were measured. The results and a comparison with previous results are presented in table 2 . The 601-630 and 1051-630 correlations have not been measured previously. With the exception of the $601-630-834 \mathrm{keV}$ correlation, all of the correlation coefficients determıned in this work differ from previously publıshed results 9,10 ) Earlier correlation measurements 9,10 ) used some combination of $\mathrm{NaI}(\mathrm{T} 1)$, or $\mathrm{NaI}(\mathrm{T} 1)$ and $\mathrm{Ge}(\mathrm{Li})$ detectors. The present measurements were made utIlizing two large volume $\mathrm{Ge}(\mathrm{L} 1)$ detectors. This system enables one to gate the photopeaks of interest and to account for interfering correlations more precisely.

The spins and parities of the ground state, 834, 1728, 2065 and $2514 \mathrm{keV}$ levels have been determined $5,6,8-10$ ). The directional correlation measurements of Monahan and Arns ${ }^{9}$ ) limited the spin of the $2065 \mathrm{keV}$ level to 1 or 3 . They assign a spin of 3 on the basis that there is no observed transition to the ground state from this level. The analysis of the present $601-630 \mathrm{keV}$ correlation, using $\delta(630)=10.3 \pm 1.3$ from the present $630-834 \mathrm{keV}$ correlation, is only consistent with a $3(\mathrm{D}, \mathrm{Q}) 2(\mathrm{M} 1, \mathrm{E} 2) 2$ sequence and a mixing ratio $\delta(601)=46_{-25}^{+\infty}$

The mixing ratio of the $894 \mathrm{keV}$ transition was determined from the $894-834 \mathrm{keV}$ transitions to be $\delta(894)=-0.039 \pm 0.009$, using the fact that the $834 \mathrm{keV}$ transition is pure E2. This mixing ratıo yields an octupole content $0.0009 \leqq O(894) \leqq 0.0023$, compared to the single particle estimate $(\mathrm{M} 3 / \mathrm{E} 2)=94 \times 10^{-5}$. The anomaly of the large enhancement of M3 over E2 mode mentioned in the previous work ${ }^{9}$ ) is considerably reduced.

The 1051-834 keV correlations yields two possible mixing ratios, $\delta(1051)=8_{-4}^{+24}$ or $\delta(1051)=0.30_{-0}^{+0} \frac{12}{10}$. For either mixing ratio, the partial coefficient $A_{2}(1051)=$ $0503 \pm 0.120$. This partial coefficient together with the mixing ratio, $\delta(630)=103 \pm$ 1.3 , and the conversion coefficients $\alpha_{\mathrm{T}}(\mathrm{E} 2)=0.119 \times 10^{-2}$ and $\beta_{\mathrm{T}}(\mathrm{M} 1)=0.841 \times$ $10^{-3}$ obtained from the tables of Hager and Seltzer ${ }^{15}$ ) are used in the method of Anicin et al. ${ }^{11}$ ) to determine from the $1051-630-834 \mathrm{keV}$ correlation

$$
T(\mathrm{E} 0) / T\left(\mathrm{E} 2_{\gamma}\right) \leqq 0.042
$$

for the $630 \mathrm{keV} 2^{+\prime} \rightarrow 2^{+}$transition. The E0 content of the $630 \mathrm{keV}$ transition can also be determined from the $601-630-834 \mathrm{keV}$ correlation Using the conversion coef- 


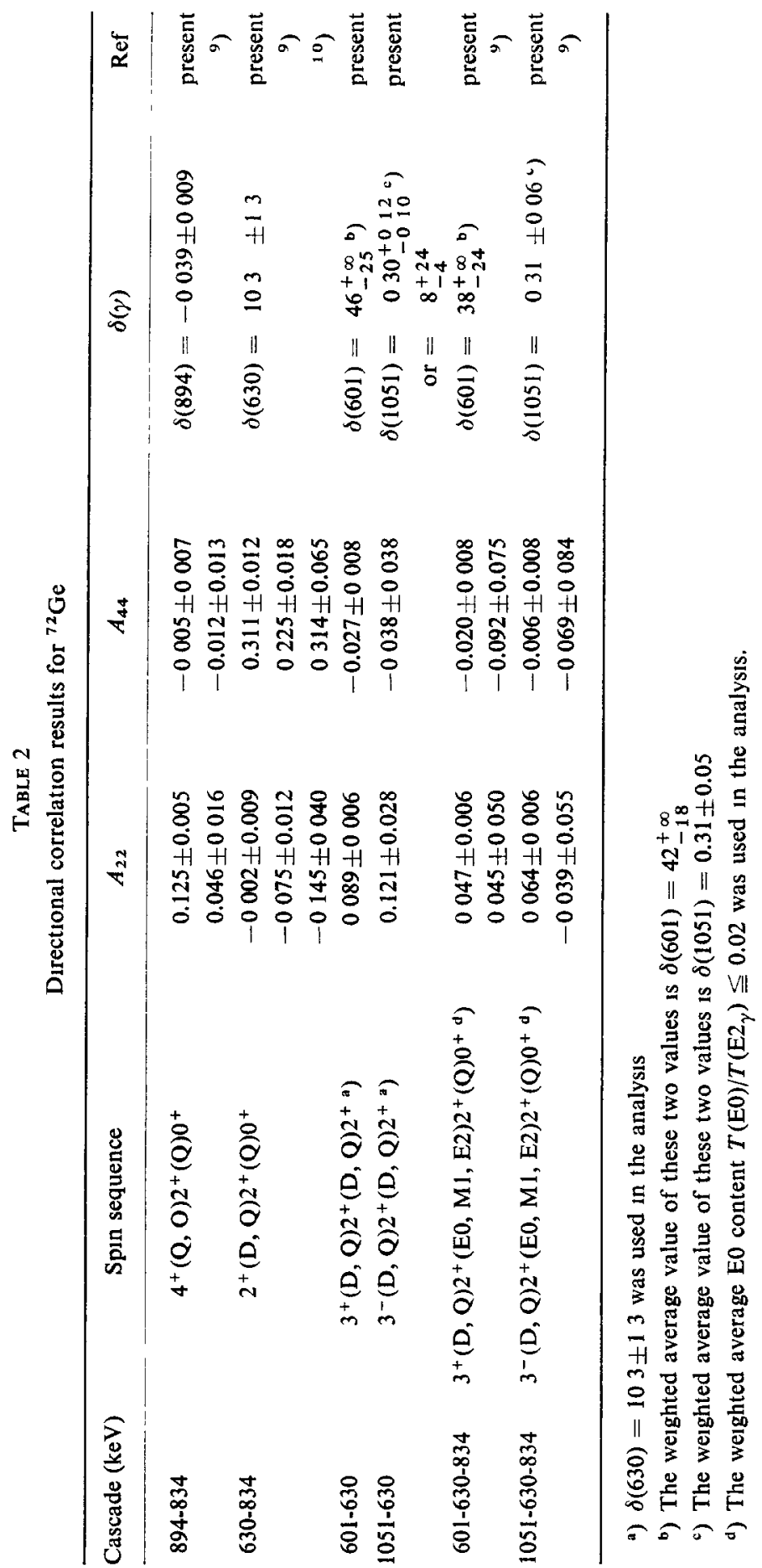


ficients given above and the $\delta(630)$ and $\delta(601)$ determıned in this experıment in the method of Anicin et al. ${ }^{11}$ ) one obtains

$$
T(\mathrm{E} 0) / T\left(\mathrm{E} 2_{\gamma}\right) \leqq 0.023 \text {. }
$$

The weighted average value $T(\mathrm{E} 0) / T\left(\mathrm{E} 2_{\gamma}\right) \leqq 0.02$ indicates that the $630 \mathrm{keV}$ transition has no more than a $2 \%$ E0 content. This is consistent with what is expected from a deformed quadrupole vibrator. The E0 content of the $630 \mathrm{keV}$ transition can now be used to determine $U_{22}(630)=0.210 \pm 0.018$ and $U_{44}(630)=0.275 \pm 0.012$. These $U_{22}$ and $U_{44}$ are used in the analysis of the 601-630-834 and 1051-630-834 keV correlations to determine $\delta(601)=38_{-24}^{+\infty}$ and $\delta(1051)=0.31 \pm 0.06$. Combining these results with the 601-630 and 1051-630 keV correlation results one obtains the werghted average values, $\delta(601)=42_{-18}^{+\infty}$ and $\delta(1051)=0.31 \pm 005$.

These results indicate that the $601 \mathrm{keV}$ transition is $\mathrm{E} 2+\left(0.06_{-0}^{+0} 11\right) \% \mathrm{M} 1$. This indicates that the $2065 \mathrm{keV}$ level is a vibrational state. They also indicate that the $1051 \mathrm{keV}$ transition is $\mathrm{E} 1+\left(8.8_{-2}^{+2} \underset{4}{7}\right) \% \mathrm{M} 2$ Consequently, the $2514 \mathrm{keV}$ level does not appear to be a vibrational state.

The authors would like to thank Al Miller for his technical assistance, and R. N. Cherry, Jr., and P. J. Wiedenbeck for their assistance in data reduction.

\section{References}

1) D. C. Camp, Nucl. Phys A121 (1968) 561

2) A C. Rester, A. V. Ramayya, J. H. Hamilton and D. Krmpotic, Nucl Phys. A162 (1971) 461

3) A. C. Rester, J. H Hamilton, A. V. Ramayya and N. R. Johnson, Nucl. Phys. A162 (1971) 481

4) H. Ottman, Z. Phys 209 (1968) 44

5) J. K. Dickens, J G. Perey and R. J. Silva, ORNL 3499, vol. 1 (1963) 20

6) M. Kregar and B. Elbek, Nucl. Phys. A93 (1967) 49

7) J. J. Kranshaar, E. Brun and W. E Meyerhof, Phys Rev 101 (1956) 139

8) F. R. Metzger, Phys. Rev. 101 (1956) 286

9) W. G. Monahan and R G Arns, Phys Rev. 184 (1969) 1135

10) R. G. Arns and M. L Wiedenbeck, Phys Rev. 112 (1958) 229

11) I. Anicin, D. Krmpotıc, A. Kukoc and R. Vukanovic, Nucl. Instr 83 (1970) 293

12) J. J Reidy and M. L. Wredenbeck, Nucl Instr. 33 (1965) 213

13) P. L. Gardulskı and M. L. Wiedenbeck, Phys. Rev. C3 (1973) 2080

14) L. C. Biedenharn and M. E Rose, Rev. Mod Phys 25 (1953) 729

15) R. S. Hager and E. C. Seltzer, Nucl. Data A4 (1968) 1

16) B. S. Dzhelepov, M. A Listengarten and S. A Shestopalova, Izv. Akad Nauk SSSR (ser fiz.) 31 (1967) 581 